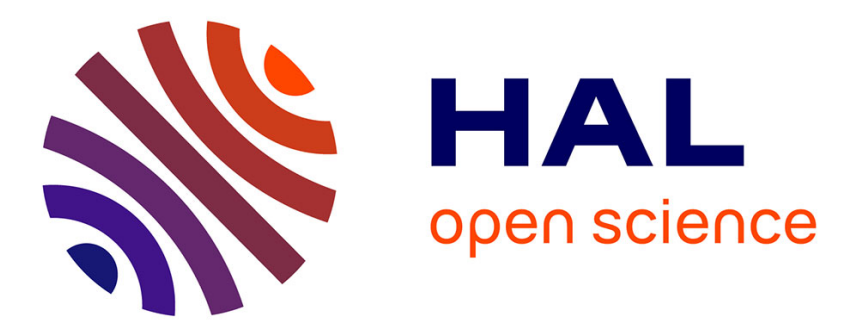

\title{
BODIPY with Tuned Amphiphilicity as a Fluorogenic Plasma Membrane Probe
}

Mayeul Collot, Emmanuel Boutant, Maxime Lehmann, Andrey Klymchenko

\section{To cite this version:}

Mayeul Collot, Emmanuel Boutant, Maxime Lehmann, Andrey Klymchenko. BODIPY with Tuned Amphiphilicity as a Fluorogenic Plasma Membrane Probe. Bioconjugate Chemistry, 2019, 30 (1), pp.192-199. 10.1021/acs.bioconjchem.8b00828 . hal-02271504

\section{HAL Id: hal-02271504 https://hal.science/hal-02271504}

Submitted on 26 Aug 2019

HAL is a multi-disciplinary open access archive for the deposit and dissemination of scientific research documents, whether they are published or not. The documents may come from teaching and research institutions in France or abroad, or from public or private research centers.
L'archive ouverte pluridisciplinaire HAL, est destinée au dépôt et à la diffusion de documents scientifiques de niveau recherche, publiés ou non, émanant des établissements d'enseignement et de recherche français ou étrangers, des laboratoires publics ou privés. 


\title{
BODIPY with Tuned Amphiphilicity as Fluorogenic Plasma Mem- brane Probe
}

\author{
Mayeul Collot, ${ }^{a *}$ Emmanuel Boutant, ${ }^{a}$ Maxime Lehmann, ${ }^{a}$ Andrey Klymchenko ${ }^{\text {**. }}$. \\ Laboratoire de Biophotonique et Pathologies, UMR 7021 CNRS, Université de Strasbourg, Faculté de Pharmacie, 74, Route \\ du Rhin, 67401 ILLKIRCH Cedex, France.
}

KEYWORDS : Plasma membrane probe, fluorogenic probe, two-photon imaging, tunneling nanotubes, spheroids.

\begin{abstract}
Staining of the plasma membrane (PM) is essential in bio-imaging as it delimits the cell surface and provides various information regarding the cell morphology and status. Herein, the lipophilicity of a green-emitting BODIPY fluorophore was tuned by gradual functionalization with anchors composed of zwitterionic and aliphatic groups, thus yielding three different amphiphilic dyes. We found that BODIPY bearing one or three anchors failed in efficiently staining the PM: derivative with one anchor showed low affinity to PM and exhibited strong fluorescence in water due to high solubility, whereas BODIPY with three anchors aggregated strongly in media and precipitated before binding to PM. In sharp contrast, the BODIPY bearing two anchors (B-2AZ, MemBright-488) formed virtually non-fluorescent soluble aggregates in aqueous medium that quickly de-aggregated in the presence of PM leading to bright soluble molecular form (quantum yield of 0.92). This fluorogenic response allowed for efficient probing of the PM at low concentration $(20 \mathrm{nM})$ with high signal to background ratio images in mono- as well as two-photon excitation microscopy. B-2AZ proved to selectively stain the PM in a more homogeneous manner than the commercially available fluorescently labelled lectin WGA. Finally, it was successfully used in 3D-imaging to reveal fine intercellular tunneling nanotubes in KB cells and to stain the PM in glioblastoma cells in spheroids.
\end{abstract}

\section{Introduction}

Among the components of eukaryotic cells, the plasma membrane $(\mathrm{PM})$ plays a prior role, as it is the natural barrier between the extracellular environment and the cytoplasm. PM is also involved in diverse biological processes including cellular uptake, neurotransmission, muscle contraction, and cell trafficking and signalling. ${ }^{1,2}$ In addition to delimiting the cell surface in bioimaging, visualizing the PM allows to check the morphology of the cell that provides information regarding the cell status such as its cell division step or the cell death including apoptosis and necrosis. ${ }^{3} 4$ The fast evolution of fluorescence imaging techniques led to the development of various molecular probes for monitoring cellular events. ${ }^{5} 6789 \mathrm{Nu}-$ merous efficient molecular probes have been designed to selectively stain specific cellular structures including mitochondria, ${ }^{10}$ endoplasmic reticulum, ${ }^{11} 1213$ lipid droplets ${ }^{14}$ or lysosomes. ${ }^{15} 16$ Nevertheless, there is still a demand for efficient and bright fluorescent PM markers. Fluorescently labelled lectins including wheat germ agglutinin (WGA) ${ }^{17}$ are among the most popular fluorescent probes for PM. Despite their efficiency and ease of use, these probes are expensive and suffer from their stability. Additionally, lectins bind glycoproteins' carbohydrates of the extracellular phase of the PM and thus are not precisely located in the lipid bilayer. We recently showed that fluorescently labeled lectins failed to stain homogeneously the PM of highly confluent cells due to a lack of accessibility in membrane-membrane contacts. ${ }^{18}$ Moreover, these lectins are not suited for studies of the lateral lipid organization of biomembranes (lipid rafts), ${ }^{19-20}$ FRET with membrane proteins ${ }^{21}$ and super-resolution imaging. ${ }^{22,}{ }^{23}$ Consequently, small molecular probes constitute a more adapted an universal alternative. Although highly hydrophobic fluorophores are efficient markers of model membranes such as liposomes, ${ }^{9}$ they generally fail in staining the cell PM of live cells as they tend to precipitate before reaching the membrane or quickly cross the PM to stain intracellular membranes. ${ }^{9,} 24$ Recent efforts have been made to develop specific and efficient molecular PM probes ${ }^{9} 25$ for cell imaging with various fluorophores: including chromone, ${ }^{26-4}$ red-emitting BODIPY, ${ }^{27}$ molecular rotor BODIPY, ${ }^{28}$ perylene, ${ }^{29}$ Nile Red, ${ }^{30}$ push-pull fluorene, ${ }^{31}$ triphenylamine, ${ }^{32}$ styryl pyridinium, ${ }^{33},{ }^{34} \mathrm{NBD},{ }^{35}$ perylene, ${ }^{29}$ and oligothiophene-based flippers. ${ }^{36,37,38,39}$ Among the fluorescent probes, fluorogenic ones offer background-free imaging due to the fact that they only emit once they reached their target. ${ }^{40,41,42,43}$ Recently, we developed a class of bright and fluorogenic plasma membrane markers based on squaraine ${ }^{44}$ and cyanines fluorophores called MemBright ${ }^{18}$ that bear two amphiphilic zwitterion moieties which insure the anchoring of the marker within the cell PM. These markers span their emission wavelengths from 570 to $830 \mathrm{~nm}$, leaving a gap to the widely used green channel. Consequently, we aimed at developing an efficient green emitting PM probe in order to access an arsenal of efficient multicolor PM fluorescent markers. To do so, the amphiphilicity of a green emitting BODIPY was tuned by incremental addition of amphiphilic zwiterionic moieties, which is a systematic approach to reveal the relationship between the probe structure and PM staining efficiency. The ability of these three fluorophores to selective- 
ly stain the PM was evaluated on cancer cells and the results showed a clear difference of behavior and efficiency. Among these dyes, B-2AZ emerged as a very bright $(\mathrm{QY}=0.92$, $\varepsilon \sim 80,000 \mathrm{M}^{-1} \cdot \mathrm{cm}^{-1}$ ) and efficient fluorogenic PM probe. In addition, B-2AZ was shown to stain the PM in more homoge- neous manner compared to fluorescently labeled lectins, thus revealing fine protrusions of the PM like filopodia and tunneling nanotubes. In 3D cells (spheroids), B-2AZ displayed deeper staining and conserved an excellent PM staining over time.

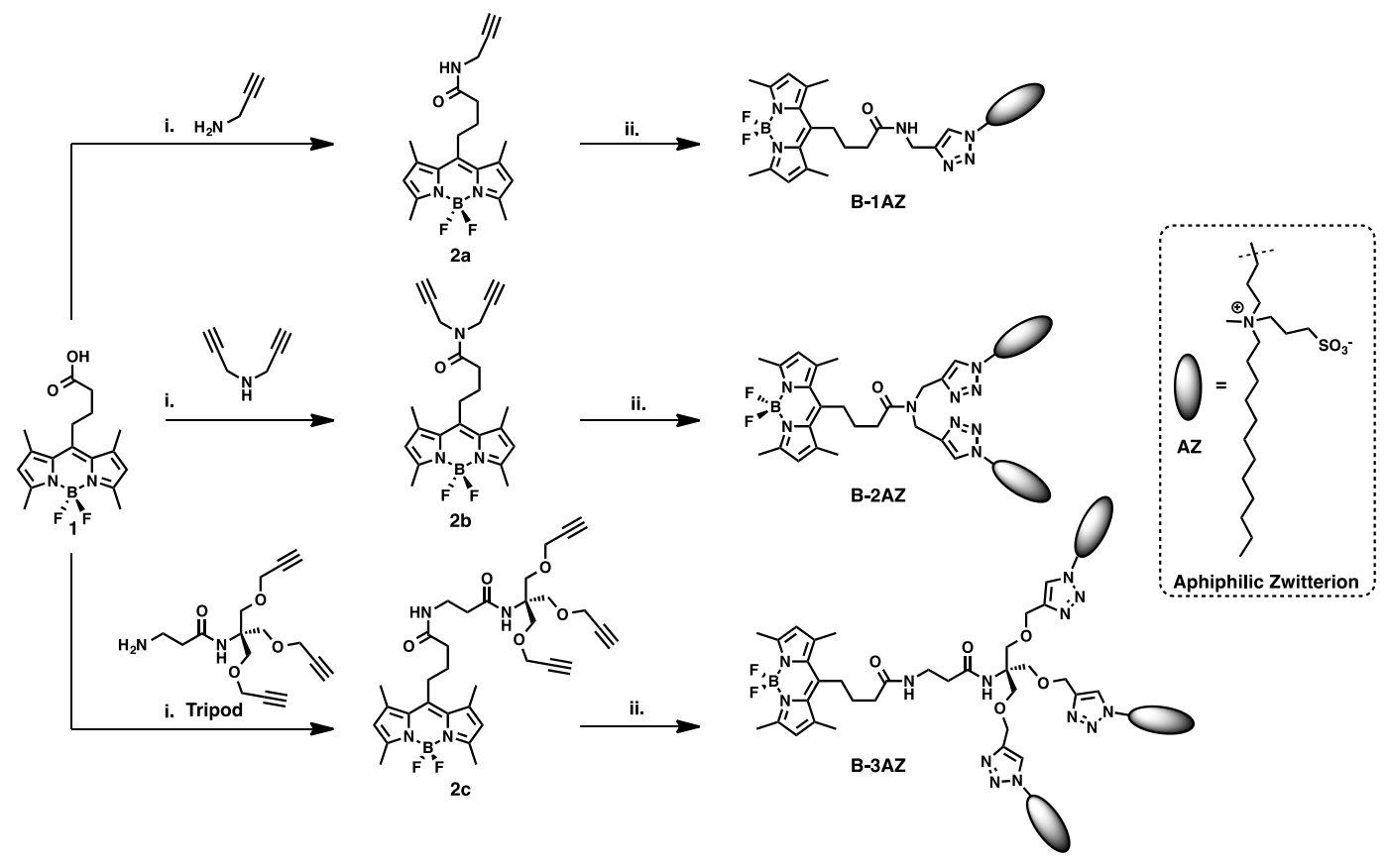

Scheme 1. Synthesis of the three amphiphilic BODIPYs. i. HATU, DIEA, DMF. ii. $\mathrm{N}_{3}-\mathrm{AZ}, \mathrm{CuSO}_{4} \cdot 5 \mathrm{H}_{2} \mathrm{O}, \mathrm{AscNa}, \mathrm{DMF}$, water, $60^{\circ} \mathrm{C}$.

\section{Results \& discussion}

\section{Design \& synthesis}

Among the green emitting fluorophores, BODIPYs present undeniable advantages for bio-imaging including high molecular extinction coefficients and elevated quantum yield which ensures high brightness as well as narrow absorption and emission bands that enable high compatibility in multicolour imaging. ${ }^{45,}{ }^{46}$ Moreover, they are efficiently excited with the widespread $488 \mathrm{~nm}$ laser as their maxima excitation wavelength is close to $500 \mathrm{~nm}$. In 2014, a PM sensor, based on a BODIPY molecular rotor was introduced. ${ }^{28}$ Although this sensor proved to be efficient in FLIM imaging for mapping the viscosity in live-cell plasma membranes, its brightness is intrinsically limited because of rational quenching, making it less adapted in more conventional fluorescence imaging like confocal microscopy. Moreover, the reported concentration that was used $(\sim 9 \mu \mathrm{M})$ could lead to detrimental effects. Therefore, we aimed at developing a fluorogenic PM probe that would be efficient regardless the viscosity of the environment and displaying a virtually non-emissive form in the medium combined with high brightness when incorporated in the PM. To this end, the amphiphilic nature of a BODIPY fluorophore was tuned by increasing combination of an amphiphilic zwitterion moiety. Although several efficient membrane probes from our group have been successfully designed with only one amphiphilic zwitterion unit combined to the fluorophore such as 3-methoxychromone (F2N12SM and FC12SM), ${ }^{26}$ environment sensitive Nile Red (NR12S) ${ }^{30}$ and 3hydroxychromone, ${ }^{47}$ in the case of squaraine dye, we proved that two amphiphilic zwitterions units were required to insure the selective staining of the plasma membrane and to avoid cell-penetration by crossing the PM. ${ }^{44}$ Squaraines and cyanines, due to their readily accessible symmetrical structures, are easily bi-functionalizable. Herein, we derivatized the acid BODIPY 1 with one to three acetylene groups (2a-2c) designed to click different numbers of amphiphilic zwitterion units leading to three BODIPYs with increasing hydrophobicity (scheme 1). 1 was synthesised in one step from glutaric anhydride and 2,4 dimethyl pyrrole via a custom and greener method than earlier reported, ${ }^{48}$ limiting the quantity of boron trifluoride to 1.5 equivalent and without any base (see SI). To this acid were coupled propargylamine, dipropargylamine and a newly designed tripod bearing 3 acetylene groups (for synthesis, see SI), respectively leading to $2 \mathrm{a}, 2 \mathrm{~b}$ and $2 \mathrm{c}$. These intermediates were reacted with a clickable amphiphilic zwitterion, giving rise to the three amphiphilic BODIPYs (scheme $1)$.

\section{Spectroscopic studies}

Spectroscopic properties of the amphiphilic BODIPYs were then evaluated in various solvents (table 1, figure S1-S3). As expected, they all displayed a bright green fluorescence in organic solvents such as methanol and DMSO with molar extinction coefficient ranging from 70,000 to $83,000 \mathrm{M}^{-1} . \mathrm{cm}^{-1}$ and quantum yield ranging from 0.73 to 0.99 . We then checked whether the dyes were sensitive to a viscous environment as membranes can display heterogeneous viscous domains. The results showed that they are poorly sensitive to high viscosity as their quantum yields in glycerol are slightly decreased compared to organic solvents. In aqueous media, B$1 \mathrm{AZ}$ bearing only one lipid anchor group, differed from its homologues as it displayed bright fluorescence in water and 
phosphate buffer with quantum yields up to 0.77 compared to 0.02 to 0.03 for B-2AZ and B-3AZ respectively. Moreover, B$1 \mathrm{AZ}$ displayed a much less broadened absorption spectrum compared to B-2AZ and B-3AZ (Figure $1 \mathrm{~A}$ ) thus showing that it is actually solubilized as a highly emissive molecular form.

Table 1. Spectroscopic properties of amphiphilic BODIPYs in various solvents and environments.

\begin{tabular}{|c|c|c|c|c|c|}
\hline Probe & Solvent & $\begin{array}{c}\text { Absmax } \\
(\mathrm{nm})\end{array}$ & $\left(\mathbf{M}^{-1} \cdot \mathbf{c m}^{-1}\right)$ & $\begin{array}{c}\mathrm{Em} \max x \\
(\mathrm{~nm})\end{array}$ & 3 \\
\hline \multirow[t]{6}{*}{ B-1AZ } & Water & 497 & 57000 & 504 & 0.77 \\
\hline & buffer $^{1}$ & 497 & 53000 & 504 & 0.67 \\
\hline & Glycerol & 500 & 74500 & 506 & 0.56 \\
\hline & $\mathrm{MeOH}$ & 497 & 70000 & 504 & 0.75 \\
\hline & DMSO & 499 & 68000 & 507 & 0.81 \\
\hline & DOPC vesicles ${ }^{2}$ & 499 & 70000 & 505 & 0.95 \\
\hline \multirow[t]{6}{*}{ B-2AZ } & Water & 500 & 47000 & 505 & 0.03 \\
\hline & buffer $^{1}$ & 500 & 50000 & 506 & 0.02 \\
\hline & Glycerol & 501 & 65000 & 506 & 0.43 \\
\hline & $\mathrm{MeOH}$ & 497 & 81000 & 504 & 0.73 \\
\hline & DMSO & 499 & 83000 & 507 & 0.88 \\
\hline & DOPC vesicles ${ }^{2}$ & 500 & 71000 & 506 & 0.92 \\
\hline \multirow[t]{6}{*}{ B-3AZ } & Water & 500 & 48000 & 512 & 0.02 \\
\hline & buffer $^{1}$ & 501 & 52000 & 508 & 0.02 \\
\hline & Glycerol & 501 & 59000 & 506 & 0.60 \\
\hline & $\mathrm{MeOH}$ & 497 & 72000 & 504 & 0.79 \\
\hline & DMSO & 499 & 73000 & 506 & 0.99 \\
\hline & DOPC vesicles ${ }^{2}$ & 499 & 65000 & 505 & 0.84 \\
\hline
\end{tabular}

\section{${ }^{1} 20 \mathrm{mM} \mathrm{pH} 7.4$}

2 DOPC: Dioleoylphosphatidylcholine $200 \mu \mathrm{M}$ (lipid concentration) in phosphate buffer $20 \mathrm{mM} \mathrm{pH} \mathrm{7.4.}$

${ }^{3}$ Quantum yields were calculated with fluorescein as a reference in $\mathrm{NaOH} 0.1 \mathrm{M}(\mathrm{QY}=0.95)^{49}$

On the other hand, broadening of the absorption spectra and the increase of their blue-shifted shoulder $(\sim 475 \mathrm{~nm})$ in case of B-2AZ and B-3AZ (Figure 1A, dashed lines), bearing additional anchor groups, suggested the formation of non-emissive aggregated species. ${ }^{50}$ In order to confirm the formation of aggregates, DLS (dynamic light scattering) measurements were performed on aqueous solutions of the amphiphilic BODIPYs. The results showed that, unlike B-1AZ present as the molecular form in water (size $<1 \mathrm{~nm}$ ), B-2AZ and B-3AZ formed $23.8 \mathrm{~nm}$ and $42.3 \mathrm{~nm}$ size nanoparticles respectively (Figure S4).

In a second step, we evaluated the behaviour of the dyes in the presence of DOPC vesicles as a model of cell PM. In all cases, the absorption spectra sharpened (Figure 1A, solid lines), especially for B-2AZ and B-3AZ depicting a deaggregation process of the dyes in the vesicles leading to an increase in fluorescence (Figure 1 B). Moreover, the three dyes reached high quantum yields values once partitioned into the vesicles $(0.84$ to 0.95$)$. Due to its good water solubility and, therefore, bright fluorescence in aqueous media B-1AZ displayed a weak fluorescence enhancement between phosphate buffer and DOPC vesicles. By contrast, B-2AZ and B$3 \mathrm{AZ}$ enhanced their quantum yields more than 40-fold (Figure $1 \mathrm{D})$. In order to determine how fast the dye de-aggregates in the presence of membrane models, kinetics studies were performed in the presence of DOPC vesicles where the fluorescence was monitored over the time (Figure $1 \mathrm{C}$ ). As expected for B-1AZ the fluorescence intensity reached its maximum instantaneously as the dye is free in solution and does not need time to de-aggregate. Conversely, B-2AZ and B-3AZ, which are aggregated in aqueous media, require more time to reach their plateau of maximum fluorescence. B-3AZ displayed the slowest membrane binding kinetics, probably because three amphiphilic anchor groups lead to a more hydrophobic molecule, thus slowing down the de-aggregation process. In the light of these results, B-2AZ and B-3AZ appeared to be the best candidates as potent fluorogenic fluorescent plasma membrane probes since their background fluorescence in aqueous media is low and once inserted in membranes they turn on their fluorescence to reach high quantum yields.
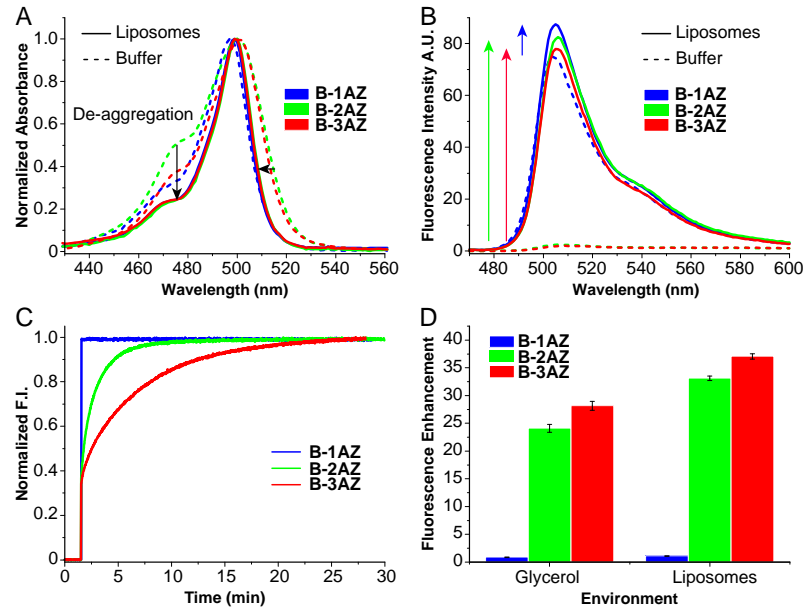

Figure 1. Normalized absorption (A) and emission (B) spectra of the 3 amphiphilic BODIPYs $(1 \mu \mathrm{M})$ in phosphate buffer alone (20

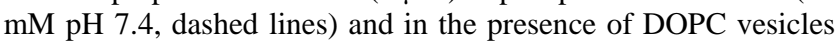
( $200 \mu \mathrm{M}$, spectra measured after $1 \mathrm{~h}$, solid lines). The arrows depict the de-aggregation effects namely: decrease of the shoulder, sharpening of the peak and fluorescence enhancement. Absorption spectra in the presence of vesicles were corrected from scattering. (C) Kinetic of de-aggregation of the amphiphilic dyes $(1 \mu \mathrm{M})$ in the presence of DOPC vesicles $(200 \mu \mathrm{M})$, the fluorophores were added after 90 seconds and the fluorescence was monitored at 505 $\mathrm{nm}\left(\lambda_{\mathrm{ex}}=460 \mathrm{~nm}\right)$. (D) Fluorescence enhancement $\left(\mathrm{FI} / \mathrm{FI}_{0}\right)$ of the dye $(1 \mu \mathrm{M})$ in glycerol and in the presence of DOPC vesicles $\left(\mathrm{F}_{0}\right.$ is the fluorescence intensity in phosphate buffer).

\section{Cellular imaging}

Next, we investigated the potential of these amphiphilic BODIPYs as PM probes in live cell experiments. To this regard, freshly diluted solutions of probes in HBSS $(20 \mathrm{nM})$ were added to KB cells (HeLa cells derivatives) without washing step. WGA-647, a PM marker based on a far-red fluorophore labelled lectin, was added to the medium prior to imaging as a control. The results showed significant differences in staining efficiency (Figure 2). Interestingly, B-2AZ rapidly and efficiently stained the PM with high signal to background ratio and clearly co-localised with WGA-647. Using the same parameters of acquisition and processing, B-1AZ failed in staining the PM. Further process of the obtained images revealed that the PM was only weakly stained by B-1AZ with very low signal to background ratio thus providing images of poor quality (Figure S5). This observation is in line with the spectroscopic studies that revealed the non-fluorogenic nature of B-1AZ. Although B-3AZ localized in the PM, it displayed relatively weak fluorescence signal. This inefficient staining is attributed to the slow de-aggregation of B-3AZ that finally ends up on the glass surface in form of aggregates (Figure S6). 
Images taken 90 min after the staining showed nearly the same profile for each dye, proving the capacity of B-2AZ to stain rapidly and efficiently the cell PM, even for long term incubation (Figure S7). Remarkably, when cells were incubated with $\mathrm{B}-2 \mathrm{AZ}$ for $3 \mathrm{~h}$ and $6 \mathrm{~h}$, the PM staining remained excellent, whereas B-3AZ failed to stain efficiently PM (Figure S8). Before going further with B-2AZ, cell viability test (MTT) was performed and the results showed that it was not cytotoxic in all tested concentrations up to $1 \mu \mathrm{M}$ (Figure S9).
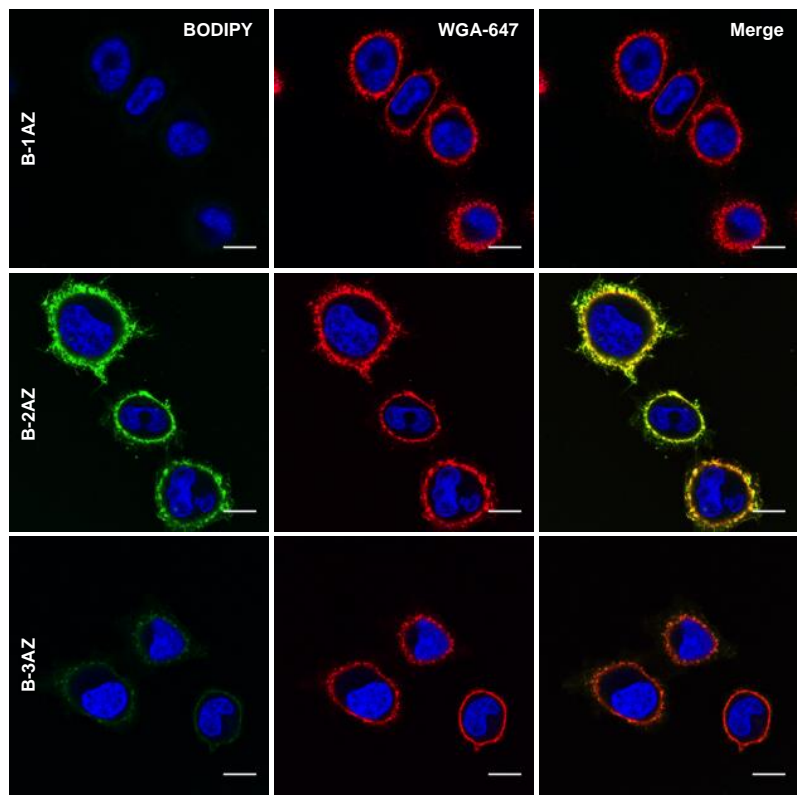

Figure 2. Laser scanning confocal microscopy images of KB cells stained with the amphiphilic BODIPYs $(20 \mathrm{nM})$ without any washing step. Images were taken 10 minutes after addition of the dyes. WGA-647 $(2 \mu \mathrm{g} / \mathrm{mL})$ is a far red emitting labelled lectin used to co-localize the plasma membrane. The nucleus was stained with Hoechst prior to imaging $(5 \mu \mathrm{g} / \mathrm{mL})$. Images were acquired and processed with the same parameters. Scale bar is 15 $\mu \mathrm{m}$.

In order to assess the specificity of the PM labelling with B2AZ, Z-stack of $20 \mu \mathrm{m}$ height was performed on live and fixed (4\% PFA) KB cells using laser scanning confocal imaging. Orthogonal projections evidenced the efficient and specific PM staining with both live and fixed cells as very weak signal could have been detected in the cytoplasm (Figure 3A and B respectively). These experiments allowed to obtaining good quality 3D-images of $\mathrm{KB}$ cells displaying their morphology as well as their thin PM processes (Figure 3C, see also supplementary movie 1). In bioimaging, the photostability of the probes is another important factor as it allows long-term imaging to monitor biological events over the time. To assess its photostability, KB cells were stained with B-2AZ and imaged upon continuous illumination by laser scanning microscopy for 15 minutes. The results showed that B-2AZ displayed a good photostability since less than $10 \%$ of the fluorescence intensity was lost after 680 consecutive scans (Figure S10 and supplementary movie 2). Additionally, since green-emitting BODIPY fluorophore was already shown to efficiently absorb two-photon light at long wavelengths (over $900 \mathrm{~nm}$ ), ${ }^{51}{ }^{52}$ we explored the ability of B-2AZ to be used in two-photon excitation (TPE) fluorescence microscopy. To this end, fixed HeLa cells were labelled with B-2AZ and subsequently imaged by TPE. The obtained imaged and intensity plot profile displayed high signal to background ratio ( 20) of the PM using $100 \mathrm{nM}$ concentration of B-2AZ and an excitation wavelength of 1000 $\mathrm{nm}$ (Figure S11). The imaging revealed that the staining of the filopodia by B-2AZ seemed more effective than that by WGA647 (Figure 4A). Filopodia are thin PM protrusions that function as antennae for cells to probe their environment, thus playing an important role in cell migration, neurite outgrowth and wound healing. ${ }^{53}$ Consequently, efficient staining of filopodia should not be neglected and is of prior importance for the above stated domains. In order to compare this difference of efficiencies, the ratio of intensities between B-2AZ and WGA-647 in sections of PM was normalized to 1 . We then measured this ratio on sections of filopodia and found that $\mathrm{B}$ 2AZ stained $>3$-fold more efficiently the filopodia than WGA647 (Figure 4A, B). This could be attributed to the fact that B2AZ diffuses within the whole plasma membrane regardless the glycoprotein composition of its extracellular layer whereas WGA-647 binding depends on the presence of glycoproteins and the nature of their glycosylation on the PM. Additionally, due to its homogeneous and intense PM staining, B-2AZ was able to reveal the presence of intercellular nanotubes (Figure 4C). The latters, also called tunneling nanotubes, are thin PM tubes connecting two individual cells and are involved in cellcell communication. ${ }^{52,55,56}$ Further analysis of the obtained image gave the tube length of $30 \mu \mathrm{m}$ and the intensity plot profile furnished a thickness of $0.36 \mu \mathrm{m}$ (Figure 4D). The latter corresponds to the diffraction limited resolution of optical microscopy, ${ }^{7}$ indicating that these tubes are probably thinner. 

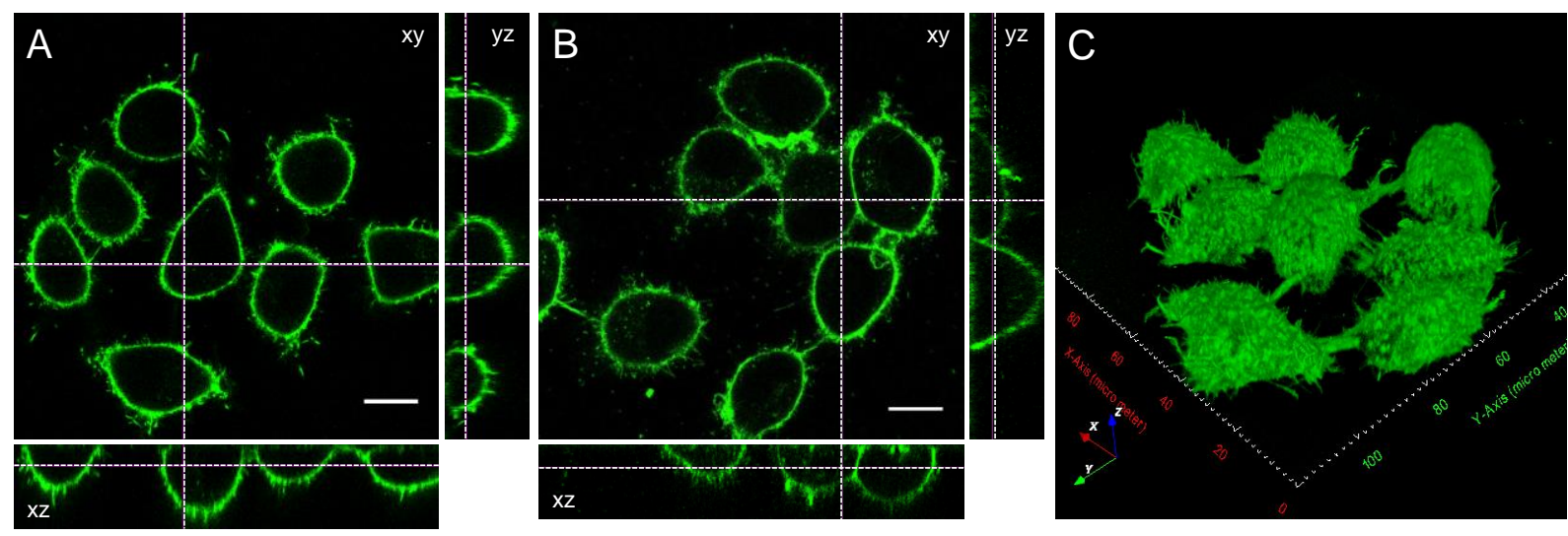

Figure 3. Laser confocal microscopy images of live (A) and 4\% PFA fixed (B) KB cells stained with the B-2AZ (20 nM) and the orthogonal projections in the $\mathrm{xz}$ and yz plans. Scale bar is $15 \mu \mathrm{m}$. (C) 3D-image of fixed $4 \%$ PFA fixed KB cells.
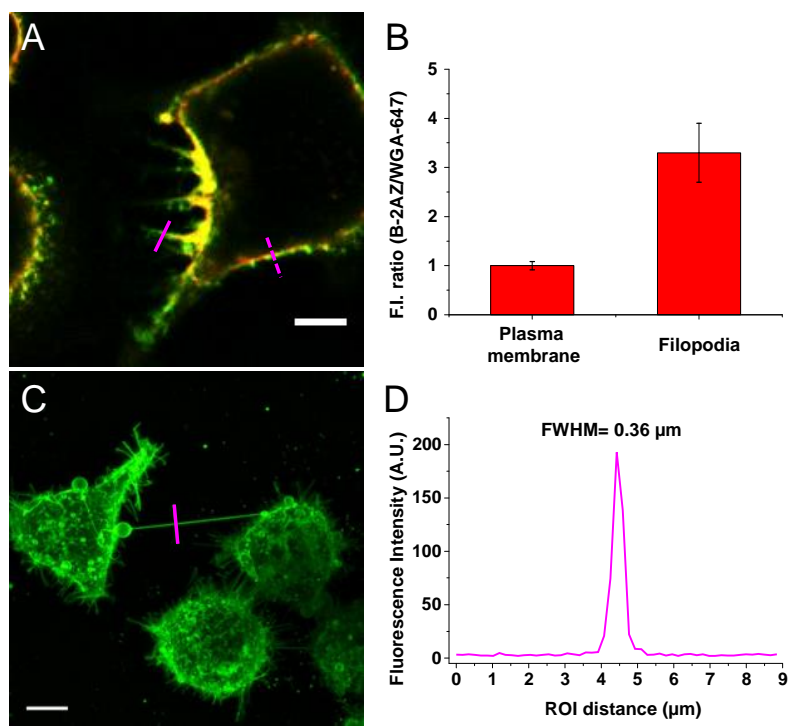

Figure 4. (A) KB cell labeled with $\mathrm{B}-2 \mathrm{AZ}$ (20 nM, green color) and WGA-647 (2 $\mu \mathrm{g} / \mathrm{mL}$, red color). Scale bar is $7 \mu \mathrm{m}$. (B) Relative distribution of WGA-647 and B-2AZ in the plasma membrane (dotted magenta line in $\mathrm{A}$, the value was normalized to 1 ) and filopodia (solid magenta line in A) 10 minutes after addition of the markers. Each measure was performed on 20 different sections of different cells from different images. (C) Max projection intensity of a Z-stack experiment (68 slices of $300 \mathrm{~nm}$ thicknesses, total height of $20.4 \mu \mathrm{m}$ ) revealing the presence of an intercellular nanotube between fixed KB cells. Scale bar is $10 \mu \mathrm{m}$. (D) Intensity profile of the ROI (magenta line in $\mathrm{C}$ ) giving a nanotube thickness of $360 \mathrm{~nm}, \mathrm{FWHM}$ is the half width at half maximum of the peak.

Finally we assessed the ability of B-2AZ to efficiently stain the PM in live 3D cell culture (spheroids). To this endeavour, live U87 glioblastoma cells in spheroids of $\sim 300 \mu \mathrm{m} \operatorname{size}^{57}$ were incubated for $3 \mathrm{~h}$ in the presence of WGA-488 and B2AZ before being imaged by laser scanning confocal microscopy at various heights (Figure 5). On the one hand, WGA488 showed clear-cut signs of internalization in the cells (Figure 5B) and did not allow the visualization of individual cells at $50 \mu \mathrm{m}$ height (Figure 5C), probably due to inefficient diffusion through tightly packed cells in the spheroid. By contrast, B-2AZ conserved a high specificity toward the PM with virtually no intracellular fluorescence (Figure 5E), thus allowing the delimitation of the cells within the spheroids (Figure $5 \mathrm{~F}$ ). These results show that $\mathrm{B}-2 \mathrm{AZ}$ is suitable for long term imaging of the PM in thicker samples like spheroids, tissues or organoids, presenting clear advantages over fluorescently labelled WGA.

\section{Conclusion}

In this study, we pointed out the importance of designing new PM fluorescent probes by modulating their amphiphilic nature. The molecular design we proposed helped to define a balance (two amphiphilic C12 moieties) that leads to quenched aggregates in aqueous media that are able to efficiently and rapidly disassemble in the presence of the PM. The amphiphilic moieties act as efficient anchors to the PM without affecting the homogeneous spreading within the latter. B-2AZ has proved to be an excellent and easy to use fluorogenic PM marker at very low concentration and without any washing step. Thanks to its narrow emission spectrum and high brightness, and high photostability it is a suitable candidate for multicolour imaging experiments in both mono- and two-photon excitation. Compared to the commercially available fluorescently labelled lectin WGA (488 and 647), B-2AZ displayed a more homogeneous staining and was able to reveal thin tunnelling nanotubes in 3D imaging as well. Additionally, in contrast to labelled WGA, B2-AZ showed highly specific staining of PM of glioblastoma spheroids and enabled delimiting individual cells with significantly better penetration depth. The efficacy of B-2AZ led us to adopt it in the MemBright family ${ }^{18}$ and rename it as MemBright-488.

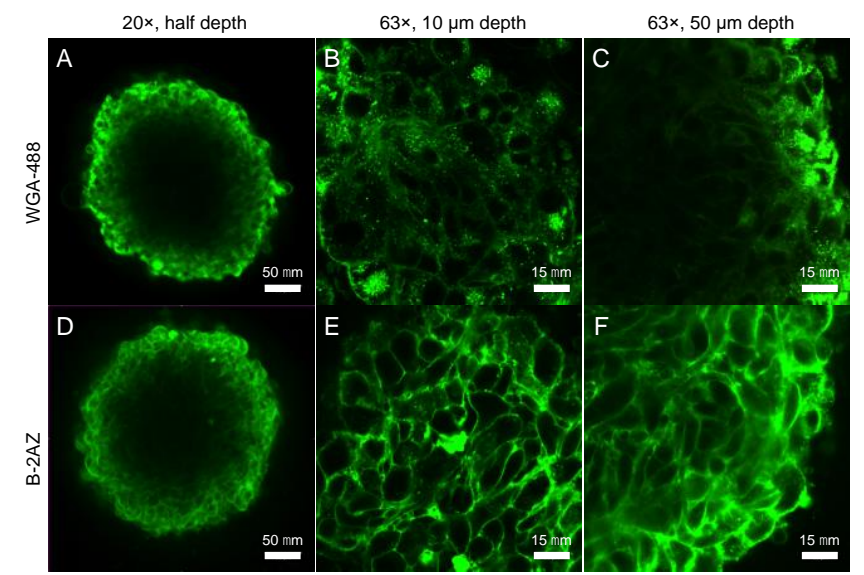


Figure 5. Laser scanning confocal images of U87 glioblastoma spheroids stained with $10 \mu \mathrm{g} / \mathrm{mL}$ WGA-488 (A, B, C) and with $200 \mathrm{nM} \mathrm{B}-2 \mathrm{AZ}$ (D, E, F) at various height. Excitation was at 488 $\mathrm{nm}$ and emission was collected between 495 and $550 \mathrm{~nm}$.

\section{Materials \& Methods}

Synthesis

Synthesis, protocols, characterizations and spectra are described in the supporting information. NMR spectra were recorded on a Bruker Avance III $400 \mathrm{MHz}$ spectrometer. Mass spectra were obtained using an Agilent Q-TOF 6520 mass spectrometer.

\section{Lipid Vesicles}

Dioleoylphosphatidylcholine (DOPC) and cholesterol were purchased from Sigma-Aldrich. Large unilamellar vesicles (LUVs) were obtained by the extrusion method as previously described. ${ }^{58}$ Briefly, a suspension of multilamellar vesicles was extruded by using a Lipex Biomembranes extruder (Vancouver, Canada). The size of the filters was first $0.2 \mu \mathrm{m}$ (7 passages $)$ and thereafter $0.1 \mu \mathrm{m}$ (10 passages). This generates monodisperse LUVs with a mean diameter of $0.11 \mu \mathrm{m}$ as measured with a Malvern Zetasizer Nano ZSP (Malvern, U.K.). LUVs were labelled by adding $5 \mu \mathrm{L}$ of probe stock solution in dimethyl sulfoxide to $1-\mathrm{mL}$ solutions of vesicles. A $20 \mathrm{mM}$ phosphate buffer, $\mathrm{pH} 7.4$, was used in these experiments. Molar ratios of probes to lipids were generally 1 to 500-1000.

\section{Spectroscopy}

Absorption spectra were recorded on a Cary 4000 spectrophotometer (Varian) and fluorescence spectra on a Fluoromax 4 (Jobin Yvon, Horiba) spectrofluorometer. Fluorescence emission spectra were systematically recorded at room temperature, unless indicated. All the spectra were corrected from wavelength-dependent response of the detector. The fluorescence and absorption spectra of the corresponding blank suspension of lipid vesicles without the probe was subtracted from these spectra.

\section{DLS measurements}

The sizes of the particles formed by The BODIPY probes in water were measured by Dynamic Light Scattering (DLS) using a Malvern Zetasizer Nano ZSP (Malvern, U.K.). Concentration of the dye was $1 \mu \mathrm{M}$. Laser wavelength was 633 nm.

\section{Cellular studies}

KB cells (ATCC® CCL-17) were grown in minimum essential medium (MEM, Gibco-Invitrogen) with $10 \%$ fetal bovine serum (FBS, Lonza), 1\% non-essential amino acids (GibcoInvitrogen), 1\% MEM vitamin solution (Gibco-Invitrogen), $1 \%$ L-Glutamine (Sigma Aldrich) and $0.1 \%$ antibiotic solution (gentamicin, Sigma-Aldrich) at $37^{\circ} \mathrm{C}$ in humidified atmosphere containing $5 \% \mathrm{CO}_{2}$. Cells were seeded onto a chambered coverglass (IBiDiß) at a density of $5 \times 10^{4}$ cells/well $24 \mathrm{~h}$ before the microscopy measurement. HeLa cells (ATCC $®$
CCL-2) and U87 cells (ATCC® HTB-14 ${ }^{\mathrm{TM}}$ ) were grown in Dulbecco's modified Eagle medium (DMEM, GibcoInvitrogen), supplemented with $10 \%$ fetal bovine serum (FBS, Lonza) and $1 \%$ antibiotic solution (penicillin-streptomycin, Gibco-Invitrogen) at $37^{\circ} \mathrm{C}$ in humidified atmosphere containing $5 \% \mathrm{CO}_{2}$. Cells were seeded onto a chambered coverglass $\left(\mathrm{IBiDi}{ }^{\circledR}\right)$ at a density of $1 \times 10^{5}$ cells/well $24 \mathrm{~h}$ before the microscopy measurement. For a nuclear staining, the medium was replaced by Hoechst $33258(5 \mu \mathrm{g} / \mathrm{mL})$ in Opti-MEM (Gibco-Invitrogen) and the cells were incubated for 10 minutes at $37^{\circ} \mathrm{C}$. For imaging, the medium was removed and the attached cells were washed with HBSS (Gibco-Invitrogen) three times. Then, a freshly prepared solution of amphiphilic BODIPY in HBSS (20 nM) was quickly added to the cells without any washing step. Prior to imaging, PM was costained by addition of wheat germ agglutinin-Alexa-647, WGA-AlexaFluor®647 (1 mg/mL in water) at a final concentration of $2 \mu \mathrm{g} / \mathrm{mL}$. Spheroids were obtained with 2-days old U87 cells according to a published protocol ${ }^{57}$ and were incubated for $3 \mathrm{~h}$ in serum-free opti-MEM medium in the presence of the dyes and were directly images without any washing steps. Confocal microscopy experiments were performed by using a Leica TCS SPE-II with HXC PL APO 63x/1.40 OIL CS objective. The microscope settings were: $405 \mathrm{~nm}$ laser for excitation of Hoechst 33258, emission was collected between 420 and $470 \mathrm{~nm} ; 488 \mathrm{~nm}$ laser for excitation of amphiphilic BODIPY, emission was collected between 500 and $550 \mathrm{~nm}$ and $632 \mathrm{~nm}$ laser for WGA-AlexaFluor®647, emission was collected between 640 and $800 \mathrm{~nm}$. The images were processed with the ImageJ or Icy software.

\section{Two-photon imaging}

Two-photon laser scanning microscopy was performed with a TriM Scope II (LaVision BioTec GmbH, Germany) with a 20x0.95 NA water immersion objective (Olympus, Japan). For 2-photon excitation a tunable infrared laser (Insight DS+ with Dual Option, Spectra Physics, France) was used and set to $1000 \mathrm{~nm}$. Fluorescence light was separated from excitation light with a SP715 filter, split by dichroic mirrors and detected by non-descanned GaAsP photomultiplier tubes (PMTs) (H7422-40, Hamamatsu Photonics, Japan).

\section{Cytotoxicity assay}

Cytotoxicity assay of B-2AZ was quantified by the MTT assay (3-(4,5-dimethylthiazol-2-yl)-2,5-diphenyltetrazolium bromide). A total of $1 \times 10^{4} \mathrm{~KB}$ cells/well were seeded in a 96well plate $24 \mathrm{~h}$ prior to the cytotoxicity assay in Dulbecco's Modified Eagle Medium (Gibco Lifetechnologies -DMEM) complemented with $10 \%$ fetal bovine serum, Penicilin (100 $\mathrm{UI} / \mathrm{mL})$, Streptomycin $(100 \mu \mathrm{g} / \mathrm{mL})$, L-Glutamine $(2 \mathrm{mM})$ and were incubated in a $5 \% \mathrm{CO}_{2}$ incubator at $37^{\circ} \mathrm{C}$. After medium removal, an amount of $100 \mu \mathrm{L}$ DMEM containing $1000 \mathrm{nM}$, $200 \mathrm{nM}$ or $20 \mathrm{nM}$ of $\mathrm{B}-2 \mathrm{AZ}$ was added on the $\mathrm{KB}$ cell and incubated during $1 \mathrm{~h}$ at $37^{\circ} \mathrm{C}\left(5 \% \mathrm{CO}_{2}\right)$. As control, for each 96-well plate, the cells were incubated with DMEM containing the same percentage of DMSO $(0,5 \% \mathrm{v} / \mathrm{v})$ as the solution with the tested dye or with Triton $1 \%$ as a positive control of cytotoxicity. After $1 \mathrm{~h}$ of dye incubation, the medium was replaced by $100 \mu \mathrm{L}$ of a mix containing DMEM + MTT solution (diluted in PBS beforehand) and the cells were incubated during $4 \mathrm{~h}$ at $37^{\circ} \mathrm{C}$. Then, $75 \mu \mathrm{L}$ of the mixture was replaced by 
$50 \mu \mathrm{L}$ of DMSO (100\%) and gently shaken for $15 \mathrm{~min}$ at room temperature in order to dissolve the insoluble purple formazan reduced in living cells. The absorbance at $540 \mathrm{~nm}$ was measured (absorbance of B-2AZ at $540 \mathrm{~nm}$ was taken into account). Each concentration of dye was tested in sextuplicate in 3 independent assays. For each concentration, we calculated the percentage of cell viability in reference of the control DMEM+ 0,5\% DMSO.

\section{ASSOCIATED CONTENT}

\section{Supporting Information}

The Supporting Information is available free of charge on the ACS Publications website.

-Supplementary information (PDF) contains data on synthesis protocol, ${ }^{1} \mathrm{H} ;{ }^{13} \mathrm{C}$ NMR and mass spectra; spectroscopy, additional cellular imaging and cytotoxicity assays.

- Supplementary movie 1 (.avi) showing 3D imaging of KB cells is also available.

\section{AUTHOR INFORMATION}

\section{Corresponding Author}

- E-mail: mayeul.collot@unistra.fr

- E-mail: andrey.klymchenko@unistra.fr

\section{Funding Sources}

This work was supported by ERC Consolidator grant BrightSens 648528 .

\section{Acknowledgements}

We thank Romain Vauchelles for his assistance at the PIQ platform, Pauline Meyer for the mass measurements as well as Tkhe Kyong Fam for the preparation of the cells.

\section{REFERENCES}

(1) Lingwood, D.; Simons, K. Lipid Rafts As a MembraneOrganizing Principle. Science 2010, 327 (5961), 46-50. https://doi.org/10.1126/science.1174621.

(2) Sezgin, E.; Levental, I.; Mayor, S.; Eggeling, C. The Mystery of Membrane Organization: Composition, Regulation and Roles of Lipid Rafts. Nat. Rev. Mol. Cell Biol. 2017, 18 (6), 361-374. https://doi.org/10.1038/nrm.2017.16.

(3) Rello, S.; Stockert, J. C.; Moreno, V.; Gámez, A.; Pacheco, M.; Juarranz, A.; Cañete, M.; Villanueva, A. Morphological Criteria to Distinguish Cell Death Induced by Apoptotic and Necrotic Treatments. Apoptosis 2005, $10 \quad$ (1), 201-208. https://doi.org/10.1007/s10495-005-6075-6.

(4) Shynkar, V. V.; Klymchenko, A. S.; Kunzelmann, C.; Duportail, G.; Muller, C. D.; Demchenko, A. P.; Freyssinet, J.-M.; Mely, Y. Fluorescent Biomembrane Probe for Ratiometric Detection of Apoptosis. J. Am. Chem. Soc. 2007, 129 (7), 2187-2193. https://doi.org/10.1021/ja068008h.

(5) Lavis, L. D.; Raines, R. T. Bright Ideas for Chemical Biology. ACS Chem. Biol. 2008, 3 (3), 142-155. https://doi.org/10.1021/cb700248m.
(6) Giepmans, B. N. G.; Adams, S. R.; Ellisman, M. H.; Tsien, R. Y. The Fluorescent Toolbox for Assessing Protein Location and Function. Science 2006, 312 (5771), 217-224. https://doi.org/10.1126/science.1124618.

(7) Fernández-Suárez, M.; Ting, A. Y. Fluorescent Probes for Super-Resolution Imaging in Living Cells. Nat. Rev. Mol. Cell Biol. 2008, 9 (12), 929-943. https://doi.org/10.1038/nrm2531.

(8) Kobayashi, H.; Ogawa, M.; Alford, R.; Choyke, P. L.; Urano, Y. New Strategies for Fluorescent Probe Design in Medical Diagnostic Imaging. Chem. Rev. 2010, 110 (5), 2620-2640. https://doi.org/10.1021/cr900263j.

(9) Klymchenko, A. S.; Kreder, R. Fluorescent Probes for Lipid Rafts: From Model Membranes to Living Cells. Chem. Biol. 2014, 21 (1), 97-113. https://doi.org/10.1016/j.chembiol.2013.11.009.

(10) Neto, B. A. D.; Corrêa, J. R.; Silva, R. G. Selective Mitochondrial Staining with Small Fluorescent Probes: Importance, Design, Synthesis, Challenges and Trends for New Markers. RSC Adv. 2013, 3 (16), 5291-5301. https://doi.org/10.1039/C2RA21995F.

(11) Kim, H.-R.; Kumar, R.; Kim, W.; Lee, J. H.; Suh, M.; Sharma, A.; Kim, C. H.; Kang, C.; Kim, J. S. A Far-Red, Photo- and Bio-Stable Fluorescent Marker Selective to the Endoplasmic Reticulum and Its Application to Tunicamycin-Treated HeLa Cells. Chem. $\begin{array}{llll}\text { Commun. } & \mathbf{2 0 1 6}, & 52 & \text { (44), }\end{array}$ https://doi.org/10.1039/C6CC02330D.

(12) Zhang, H.; Fan, J.; Dong, H.; Zhang, S.; Xu, W.; Wang, J.; Gao, P.; Peng, X. Fluorene-Derived Two-Photon Fluorescent Probes for Specific and Simultaneous Bioimaging of Endoplasmic Reticulum and Lysosomes: Group-Effect and Localization. J. Mater. Chem. B 2013, 1 (40), 5450-5455. https://doi.org/10.1039/C3TB20646G.

(13) Arai, S.; Lee, S.-C.; Zhai, D.; Suzuki, M.; Chang, Y. T. A Molecular Fluorescent Probe for Targeted Visualization of Temperature at the Endoplasmic Reticulum. Sci. Rep. 2014, 4, 6701 https://doi.org/10.1038/srep06701.

(14) Collot, M.; Fam, T. K.; Ashokkumar, P.; Faklaris, O.; Galli, T.; Danglot, L.; Klymchenko, A. S. Ultrabright and Fluorogenic Probes for Multicolor Imaging and Tracking of Lipid Droplets in Cells and Tissues. J. Am. Chem. Soc. 2018, 140 (16), 5401-5411. https://doi.org/10.1021/jacs.7b12817.

(15) Despras, G.; Zamaleeva, A. I.; Dardevet, L.; Tisseyre, C. Magalhaes, J. G.; Garner, C.; Waard, M. D.; Amigorena, S.; Feltz, A.; Mallet, J.-M.; et al. H-Rubies, a New Family of Red Emitting Fluorescent PH Sensors for Living Cells. Chem. Sci. 2015, 6 (10), 59285937. https://doi.org/10.1039/C5SC01113B.

(16) Chen, X.; Bi, Y.; Wang, T.; Li, P.; Yan, X.; Hou, S.; Bammert, C. E.; Ju, J.; Gibson, K. M.; Pavan, W. J.; et al. Lysosomal Targeting with Stable and Sensitive Fluorescent Probes (Superior LysoProbes): Applications for Lysosome Labeling and Tracking during Apoptosis. Sci. Rep. 2015, 5, 9004 https://doi.org/10.1038/srep09004.

(17) Life Technologies https://www.thermofisher.com/.

(18) Collot, M.; Ashokkumar, P.; Anton, H.; Boutant, E.; Faklaris, O.; Galli, T.; Mely, Y.; Danglot, L.; Klymchenko, A. S. MemBright: A Family of Fluorescent Membrane Probes for Advanced Cellular Imaging and Neuroscience. Cell Chem. Biol. 2018, accepted, see also bioRxiv 2018, 380451. https://doi.org/10.1101/380451.

(19) Jin, L.; Millard, A. C.; Wuskell, J. P.; Dong, X. M.; Wu, D Q.; Clark, H. A.; Loew, L. M. Characterization and Application of a New Optical Probe for Membrane Lipid Domains. Biophys. J. 2006, 90 (7), 2563-2575. https://doi.org/10.1529/biophysj.05.072884.

(20) Owen, D. M.; Williamson, D. J.; Magenau, A.; Gaus, K. Sub-Resolution Lipid Domains Exist in the Plasma Membrane and Regulate Protein Diffusion and Distribution. Nat. Commun. 2012, 3, 1256. https://doi.org/10.1038/ncomms2273.

(21) Ziomkiewicz, I.; Loman, A.; Klement, R.; Fritsch, C.; Klymchenko, A. S.; Bunt, G.; Jovin, T. M.; Arndt-Jovin, D. J. Dynamic Conformational Transitions of the EGF Receptor in Living Mammalian Cells Determined by FRET and Fluorescence Lifetime Imaging Microscopy. Cytometry A 2013, 83 (9), 794-805. https://doi.org/10.1002/cyto.a.22311.

(22) Solanko, L. M.; Honigmann, A.; Midtiby, H. S.; Lund, F. W.; Brewer, J. R.; Dekaris, V.; Bittman, R.; Eggeling, C.; Wuestner, 
D. Membrane Orientation and Lateral Diffusion of BODIPYCholesterol as a Function of Probe Structure. Biophys. J. 2013, 105 (9), 2082-2092. https://doi.org/10.1016/j.bpj.2013.09.031.

(23) Honigmann, A.; Mueller, V.; Ta, H.; Schoenle, A.; Sezgin, E.; Hell, S. W.; Eggeling, C. Scanning STED-FCS Reveals Spatiotemporal Heterogeneity of Lipid Interaction in the Plasma Membrane of Living Cells. Nat. Commun. 2014, 5, 5412. https://doi.org/10.1038/ncomms6412.

(24) Niko, Y.; Didier, P.; Mely, Y.; Konishi, G.; Klymchenko, A. S. Bright and Photostable Push-Pull Pyrene Dye Visualizes Lipid Order Variation between Plasma and Intracellular Membranes. Sci. Rep. 2016, 6, 18870. https://doi.org/10.1038/srep18870.

(25) Laguerre, A.; Schultz, C. Novel Lipid Tools and Probes for Biological Investigations. Curr. Opin. Cell Biol. 2018, 53, 97-104. https://doi.org/10.1016/j.ceb.2018.06.013.

(26) Kreder, R.; Oncul, S.; Kucherak, O. A.; Pyrshev, K. A.; Real, E.; Mely, Y.; Klymchenko, A. S. Blue Fluorogenic Probes for Cell Plasma Membranes Fill the Gap in Multicolour Imaging. Rsc Adv. 2015, 5 (29), 22899-22905. https://doi.org/10.1039/c4ra16225k.

(27) Zhang, X.; Wang, C.; Jin, L.; Han, Z.; Xiao, Y. Photostable Bipolar Fluorescent Probe for Video Tracking Plasma Membranes Related Cellular Processes. ACS Appl. Mater. Interfaces 2014, 6 (15), 12372-12379. https://doi.org/10.1021/am503849c.

(28) López-Duarte, I.; Vu, T. T.; Izquierdo, M. A.; Bull, J. A.; Kuimova, M. K. A Molecular Rotor for Measuring Viscosity in Plasma Membranes of Live Cells. Chem. Commun. 2014, 50 (40), 5282 5284. https://doi.org/10.1039/C3CC47530A.

(29) Heek, T.; Nikolaus, J.; Schwarzer, R.; Fasting, C.; Welker, P.; Licha, K.; Herrmann, A.; Haag, R. An Amphiphilic Perylene Imido Diester for Selective Cellular Imaging. Bioconjug. Chem. 2013, 24 (2), 153-158. https://doi.org/10.1021/bc3005655.

(30) Kucherak, O. A.; Oncul, S.; Darwich, Z.; Yushchenko, D. A.; Arntz, Y.; Didier, P.; Mély, Y.; Klymchenko, A. S. Switchable Nile Red-Based Probe for Cholesterol and Lipid Order at the Outer Leaflet of Biomembranes. J. Am. Chem. Soc. 2010, 132 (13), 49074916. https://doi.org/10.1021/ja100351w.

(31) Shaya, J.; Collot, M.; Benailly, F.; Mahmoud, N.; Mély, Y.; Michel, B. Y.; Klymchenko, A. S.; Burger, A. Turn-On Fluorene Push-Pull Probes with High Brightness and Photostability for Visualizing Lipid Order in Biomembranes. ACS Chem. Biol. 2017. https://doi.org/10.1021/acschembio.7b00658.

(32) Guo, L.; Zhang, R.; Sun, Y.; Tian, M.; Zhang, G.; Feng, R.; Li, X.; Yu, X.; He, X. Styrylpyridine Salts-Based Red Emissive TwoPhoton Turn-on Probe for Imaging the Plasma Membrane in Living Cells and Tissues. Analyst 2016, 141 (11), 3228-3232. https://doi.org/10.1039/c6an00147e.

(33) Kwiatek, J. M.; Owen, D. M.; Abu-Siniyeh, A.; Yan, P.; Loew, L. M.; Gaus, K. Characterization of a New Series of Fluorescent Probes for Imaging Membrane Order. Plos One 2013, 8 (2), e52960. https://doi.org/10.1371/journal.pone.0052960.

(34) Tian, M.; Liu, Y.; Sun, Y.; Zhang, R.; Feng, R.; Zhang, G.; Guo, L.; Li, X.; Yu, X.; Sun, J. Z.; et al. A Single Fluorescent Probe Enables Clearly Discriminating and Simultaneously Imaging LiquidOrdered and Liquid-Disordered Microdomains in Plasma Membrane of Living Cells. Biomaterials 2017, 120, 46-56. https://doi.org/10.1016/j.biomaterials.2016.12.016.

(35) Concilio, S.; Ferrentino, I.; Sessa, L.; Massa, A.; Iannelli, P.; Diana, R.; Panunzi, B.; Rella, A.; Piotto, S. A Novel Fluorescent Solvatochromic Probe for Lipid Bilayers. Supramol. Chem. 2017, 29 (11), 887-895. https://doi.org/10.1080/10610278.2017.1372583.

(36) Dal Molin, M.; Verolet, Q.; Colom, A.; Letrun, R.; Derivery, E.; Gonzalez-Gaitan, M.; Vauthey, E.; Roux, A.; Sakai, N.; Matile, S. Fluorescent Flippers for Mechanosensitive Membrane Probes. J. Am. Chem. Soc. 2015, 137 (2), 568-571. https://doi.org/10.1021/ja5107018.

(37) Fin, A.; Jentzsch, A. V.; Sakai, N.; Matile, S. Oligothiophene Amphiphiles as Planarizable and Polarizable Fluorescent Membrane Probes. Angew. Chem.-Int. Ed. 2012, 51 (51), 1273612739. https://doi.org/10.1002/anie.201206446.

(38) Yan, P.; Xie, A.; Wei, M.; Loew, L. M. Amino(Oligo)Thiophene-Based Environmentally Sensitive Biomembrane
Chromophores. J. Org. Chem. 2008, 73 (17), 6587-6594. https://doi.org/10.1021/jo800852h.

(39) Colom, A.; Derivery, E.; Soleimanpour, S.; Tomba, C.; Molin, M. D.; Sakai, N.; González-Gaitán, M.; Matile, S.; Roux, A. A Fluorescent Membrane Tension Probe. Nat. Chem. 2018, 10 (11), 1118-1125. https://doi.org/10.1038/s41557-018-0127-3.

(40) Nadler, A.; Schultz, C. The Power of Fluorogenic Probes. Angew. Chem. Int. Ed. 2013, 52 (9), 2408-2410. https://doi.org/10.1002/anie.201209733.

(41) Li, X.; Gao, X.; Shi, W.; Ma, H. Design Strategies for Water-Soluble Small Molecular Chromogenic and Fluorogenic Probes. Chem. Rev. 2014, 114 (1), 590-659. https://doi.org/10.1021/cr300508p.

(42) Su, D.; Teoh, C. L.; Wang, L.; Liu, X.; Chang, Y.-T. Motion-Induced Change in Emission (MICE) for Developing Fluorescent Probes. Chem. Soc. Rev. 2017, 46 (16), 4833-4844. https://doi.org/10.1039/C7CS00018A.

(43) Klymchenko, A. S. Solvatochromic and Fluorogenic Dyes as Environment-Sensitive Probes: Design and Biological Applications. Acc. Chem. Res. 2017, 50 (2), 366-375. https://doi.org/10.1021/acs.accounts.6b00517.

(44) Collot, M.; Kreder, R.; Tatarets, A. L.; Patsenker, L. D.; Mely, Y.; Klymchenko, A. S. Bright Fluorogenic Squaraines with Tuned Cell Entry for Selective Imaging of Plasma Membrane vs. Endoplasmic Reticulum. Chem. Commun. 2015, 51 (96), 1713617139. https://doi.org/10.1039/c5cc06094j.

(45) Kowada, T.; Maeda, H.; Kikuchi, K. BODIPY-Based Probes for the Fluorescence Imaging of Biomolecules in Living Cells. Chem. Soc. Rev. 2015, 44 (14), 4953-4972. https://doi.org/10.1039/C5CS00030K.

(46) Ulrich, G.; Ziessel, R.; Harriman, A. The Chemistry of Fluorescent Bodipy Dyes: Versatility Unsurpassed. Angew. Chem. Int Ed. 2008, 47 (7), 1184-1201. https://doi.org/10.1002/anie.200702070.

(47) Klymchenko, A. S.; Oncul, S.; Didier, P.; Schaub, E.; Bagatolli, L.; Duportail, G.; Mély, Y. Visualization of Lipid Domains in Giant Unilamellar Vesicles Using an Environment-Sensitive Membrane Probe Based on 3-Hydroxyflavone. Biochim. Biophys. Acta BBA - Biomembr. 2009, 1788 (2), 495-499. https://doi.org/10.1016/j.bbamem.2008.10.019.

(48) Li, Z.; Mintzer, E.; Bittman, R. First Synthesis of Free Cholesterol-BODIPY Conjugates. J. Org. Chem. 2006, 71 (4), 1718 1721. https://doi.org/10.1021/jo052029x.

(49) Principles of Fluorescence Spectroscopy; Lakowicz, J. R., Ed.; Springer US: Boston, MA, 2006.

(50) Vu, T. T.; Dvorko, M.; Schmidt, E. Y.; Audibert, J.-F.; Retailleau, P.; Trofimov, B. A.; Pansu, R. B.; Clavier, G.; MéalletRenault, R. Understanding the Spectroscopic Properties and Aggregation Process of a New Emitting Boron Dipyrromethene (BODIPY). $J$. Phys. Chem. C 2013, 117 (10), 5373-5385. https://doi.org/10.1021/jp3097555.

(51) Xu, C.; Webb, W. W. Measurement of Two-Photon Excitation Cross Sections of Molecular Fluorophores with Data from 690 to 1050 Nm. J. Opt. Soc. Am. B 1996, 13 (3), 481. https://doi.org/10.1364/JOSAB.13.000481.

(52) Mütze, J.; Iyer, V.; Macklin, J. J.; Colonell, J.; Karsh, B.; Petrášek, Z.; Schwille, P.; Looger, L. L.; Lavis, L. D.; Harris, T. D. Excitation Spectra and Brightness Optimization of Two-Photon Excited Probes. Biophys. J. 2012, 102 (4), 934-944. https://doi.org/10.1016/j.bpj.2011.12.056.

(53) Mattila, P. K.; Lappalainen, P. Filopodia: Molecular Architecture and Cellular Functions. Nat. Rev. Mol. Cell Biol. 2008, 9 (6), 446-454. https://doi.org/10.1038/nrm2406.

(54) Önfelt, B.; Davis, D. M. Can Membrane Nanotubes Facilitate Communication between Immune Cells? Biochem. Soc. Trans. 2004, 32 (5), 676-678. https://doi.org/10.1042/BST0320676.

(55) Davis, D. M.; Sowinski, S. Membrane Nanotubes: Dynamic Long-Distance Connections between Animal Cells. Nat. Rev. Mol. Cell Biol. 2008, 9 (6), 431-436. https://doi.org/10.1038/nrm2399.

(56) Gousset, K.; Schiff, E.; Langevin, C.; Marijanovic, Z.; Caputo, A.; Browman, D. T.; Chenouard, N.; de Chaumont, F.; Martino, A.; Enninga, J.; et al. Prions Hijack Tunnelling Nanotubes for Inter- 
cellular Spread. Nat. Cell Biol. 2009, 11 (3), 328-336. https://doi.org/10.1038/ncb1841.

(57) Blandin, A.-F.; Noulet, F.; Renner, G.; Mercier, M.-C.; Choulier, L.; Vauchelles, R.; Ronde, P.; Carreiras, F.; EtienneSelloum, N.; Vereb, G.; et al. Glioma Cell Dispersion Is Driven by A5 Integrin-Mediated Cell-Matrix and Cell-Cell Interactions. Cancer
Lett.

2016,

376

https://doi.org/10.1016/j.canlet.2016.04.007.

(2),

$328-338$

(58) Hope, M. J.; Bally, M. B.; Webb, G.; Cullis, P. R. Production of Large Unilamellar Vesicles by a Rapid Extrusion Procedure: Characterization of Size Distribution, Trapped Volume and Ability to Maintain a Membrane Potential. Biochim. Biophys. Acta 1985, 812 (1), 55-65.

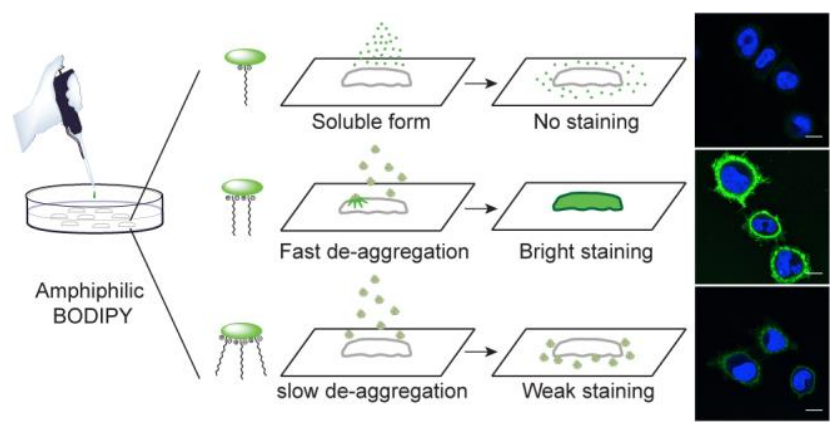

For TOC only 